\title{
Reseña / Responsabilidad Social Universitaria: El caso del Programa Nacional del Voluntariado Universitario en la UNaM
}

Dachary, M. R. (2019). Responsabilidad Social Universitaria:

el caso del Programa Nacional del Voluntariado Universitario

en la UNaM. Posadas. EDUNAM - 1ra. edición

Por Oscar Lossio

Universidad Nacional del Litoral, Argentina

olossio@hotmail.com

(iD orcid.org/0000-0001-9917-5561

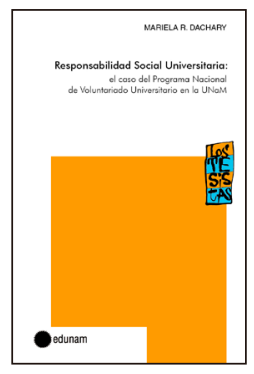

Le damos la bienvenida a un nuevo libro sobre la extensión universitaria, especialmente porque contribuye a la reflexión sobre el Programa Nacional de Voluntariado Universitario (PNVU) de la República Argentina en el período 2006-2015. Al respecto, conviene aclarar que quienes en algún momento hemos escrito algún artículo sobre el voluntariado universitario, sabemos que son escasos los antecedentes sobre la temática, más allá de la socialización de relatos de las experiencias y de los resultados de los proyectos ejecutados. Justamente, consideramos que el mayor aporte del libro es la sistematización de valiosa información acerca de dicho programa. Este se crea en el año 2006 en el ámbito de la Secretaría de Políticas Universitarias del Ministerio de Educación de la Nación y va a permitir, desde ese mismo año, el financiamiento de proyectos en distintas universidades del país a través de convocatorias anuales.

La autora, mediante esta producción de investigación, ha obtenido el título de Magíster en Políticas Sociales, por lo que analiza el PNVU en su dimensión de política pública y luego se focaliza en su implementación en el contexto específico de la Universidad Nacional del Misiones (UNaM) entre los años 2006 y 2015, para lo cual recupera las perspectivas de distintos actores universitarios (docentes directores de proyectos, estudiantes, no docentes, y autoridades de gestión). Ofrecemos a continuación una descripción de la obra y algunos interrogantes que nos ha suscitado su lectura.

En el primer capítulo, Mariela Dachary define, a su entender, las políticas públicas y realiza una contextualización histórica de las implementadas en los años 90 bajo el neoliberalismo que predominó en América Latina y en Argentina, para abordar luego los cambios en el rol del Estado desde la primera década del siglo XX. Posteriormente, con ese marco, trata específicamente aquellas políticas públicas que incidieron en la Universidad en esos dos períodos contrapuestos.

El segundo capítulo versa sobre "El paradigma de la Responsabilidad Social Universitaria" (RSU), siendo esta la perspectiva teórica desde la cual interpreta al voluntariado universitario. Es aquí donde el texto nos provocó algunos interrogantes que queremos compartir. De manera puntual, nos referimos a que pareciera, tanto en este capítulo como en el libro en general, que se da por supuesto que el PNVU responde al marco teórico de la RSU, lo que consideramos que no sería adecuado. En tal sentido, la forma de redacción no permite observar una distancia entre el propio marco teórico y el que efectivamente corresponde al programa que se analiza. Aquí conviene señalar que la perspectiva de la RSU no ha sido 
aceptada, salvo excepciones, en las universidades públicas de Argentina. Por lo tanto, las referencias bibliográficas que se citan quizás responden a esas excepciones y a quienes exponen la situación de otros países de América Latina, donde sí es utilizado ese constructo, que deviene de la Responsabilidad Social Empresaria (RSE). Subrayamos que esto sí lo advierte explícitamente la autora y toma distancia de esa posición empresarial.

Como parte de ese mismo capítulo presenta, además, una interesante vinculación entre el voluntariado y la extensión universitaria y prosigue con una pertinente caracterización y progresión histórica del PNVU, incluyendo la situación específica de la UNaM a partir de datos estadísticos.

En el tercer capítulo expone la perspectiva metodológica cualitativa de la investigación, los criterios de selección y una breve síntesis sobre los proyectos a cuyos integrantes realizó entrevistas.

En el cuarto, la autora realiza una revisión de documentos, principalmente del Consejo Interuniversitario Nacional (CIN), que complementa con los discursos de personal de gestión de la UNaM sobre las transformaciones recientes en las universidades públicas en Argentina, aludiendo especialmente al contexto de la tercera reforma de la Educación Superior en América Latina y, en ese marco, a la RSU y el PNVU, incluyendo citas de documentos específicos.

En el quinto capítulo se analizan las voces de distintos participantes de la UNaM en los proyectos del PNVU en torno a tópicos que se vinculan con las diversas formas en que se establece la relación entre el voluntariado, la participación política y el compromiso social. Consideramos que socializar las palabras de quienes "hacen" extensión siempre es importante, por lo que valoramos positivamente el trabajo que se hace en el libro en este sentido. Sin embargo, ponemos a consideración una apreciación sobre la manera en que se expone la articulación de algunos fragmentos de las entrevistas y las reflexiones que se realizan sobre ellos, ya que pareciera que las interpretaciones de la autora exceden lo que efectivamente se explicita del decir de un entrevistado, o que se usan ciertos recortes de los diálogos que no son necesariamente representativos de lo que se quiere argumentar.

En tanto, subrayamos que el sexto capítulo, que comprende las reflexiones finales, es una muy buena síntesis de todo lo tratado a lo largo del libro.

Para finalizar, sin dudas invitamos a la lectura de este libro que suponemos puede ser de utilidad, por un lado, para todos los que desarrollan prácticas de voluntariado universitario y, por otro, para el personal de gestión de la extensión. 